This is the author's final, peer-reviewed manuscript as accepted for publication. The publisher-formatted version may be available through the publisher's web site or your institution's library.

\title{
Stem cell-based photodynamic therapy
}

Tej B. Shrestha, Gwi M. Seo, Matthew T. Basel, Mausam Kalita, Hongwang Wang, David Villanueva, Marla Pyle, Deryl L. Troyer, and Stefan H. Bossmann

\section{How to cite this manuscript}

If you make reference to this version of the manuscript, use the following information:

Shrestha, T. B., Seo, G. M., Basel, M. T., Kalita, M., Wang, H., Villanueva, D., . . . Bossmann, S. H. (2012). Stem cell-based photodynamic therapy. Retrieved from http://krex.ksu.edu

\section{Published Version Information}

Citation: Shrestha, T. B., Seo, G. M., Basel, M. T., Kalita, M., Wang, H., Villanueva, D., ... Bossmann, S. H. (2012). Stem cell-based photodynamic therapy. Photochemical \& Photobiological Sciences, 11(7), 1251-1258.

Copyright: ( $\odot$ The Royal Society of Chemistry and Owner Societies 2012

Digital Object Identifier (DOI): doi:10.1039/c2pp05417e

Publisher's Link: http://pubs.rsc.org/en/Content/ArticleLanding/2012/PP/c2pp05417e

This item was retrieved from the K-State Research Exchange (K-REx), the institutional repository of Kansas State University. K-REx is available at http://krex.ksu.edu 


\title{
Stem Cell-Based Photodynamic Therapy: 1. in Vitro Studies
}

\author{
Tej B. Shrestha, $*^{a, b}$ Gwi M. Seo $^{a}$, Matthew T. Basel ${ }^{a, b}$, Mausam Kalita ${ }^{a, b}$, Hongwang Wang ${ }^{b}$, David \\ Villanueva $^{b}$, Marla Pyle ${ }^{a}$, Deryl L. Troyer $*^{a}$ and Stefan H. Bossmann* ${ }^{b}$ \\ 5 Received (in $X X X, X X X) X$ th $X X X X X X X X X 20 X X$, Accepted $X$ th $X X X X X X X X X 20 X X$ \\ DOI: 10.1039/b000000x
}

We have transfected murine neural stem cells (NSCs) with a plasmid expressing Gaussia luciferase (gLuc). The enzyme is secreted from the cells. We have used the gLuc-containing supernatant from cultured NSCs to perform in vitro photodynamic therapy of murine melanoma cells (B16F10). The

10 treatment system was comprised of 5-aminolevulinic acid as a prodrug for the synthesis of the photosensitizer protoporphyrin IX, Gaussia luciferase, and its substrate, coelenterazine. A significant reduction in the number of live melanoma cells was observed $36 \mathrm{~h}$ after coelenterazine-mediated PDT.

\section{Introduction}

In the search for new cancer treatment methods able to overcome 15 the multi-drug resistance found in many cancer types, it will be advantageous to try new approaches. Classic chemotherapy focuses on killing cells that are dividing rapidly. Unfortunately, many other cells in the body also divide rapidly, causing many of well-known chemotherapy side effects (e.g. fatigue from low red 20 blood cell count, susceptibility to infection from wiping out the white blood cells, and weight loss because of the lack of functioning intestinal cells). ${ }^{1,2}$ Classic chemotherapy often fails because these side effects prevent administering doses of these anticancer drugs adequate to kill the tumour cells.

${ }_{25}$ Photodynamic therapy (PDT) has been successful in treating nonhypoxic tumours, which were conveniently located to permit high doses of incident light. ${ }^{3}$ To date, the U.S. Food and Drug Administration (FDA) has approved the photo-sensitizing agent porfimer sodium (Photofrin $\left.{ }^{\circledR}\right)$, for use in PDT for the treatment 30 of esophageal cancer ${ }^{4}$, non-small cell lung cancer ${ }^{4}$ and of precancerous lesions in patients with Barrett's esophagus (a condition that can lead to esophageal cancer). The main obstacle to a prevalent application of PDT is not the enrichment of photodynamic drugs within tumours, but the availability of light 35 sources that provide sufficiently high doses in the appropriate excitation windows for mono-photonic and bi/multi-photonic excitation. The light absorption coefficients of water and human aorta tissue possess a minimum region of tissue absorption at $800 \pm 50 \mathrm{~nm}$. This corresponds to maximal light penetration depths $40(\delta)^{5}$ of $1 \mathrm{~cm}$ at $800 \mathrm{~nm}, 0.5 \mathrm{~cm}$ at $600 \mathrm{~nm}$ and $900 \mathrm{~nm}$, and $0.1 \mathrm{~cm}$ at $400 \mathrm{~nm} .{ }^{5,6}$ Numerous strategies for enhanced irradiation of tumours that are located within the human or mammalian body are discussed in the literature. ${ }^{7}$ Among these approaches are the use of high-energy lasers instead of lamps ${ }^{7}$, laser diodes ${ }^{8}$, fiber45 optical devices for the in situ irradiation of the interstitium ${ }^{9}$, the use of gold nanoshells and nanocages as high absorption and scattering materials ${ }^{10}$, and bi- and multi-photon excitation of suitable chromophores. ${ }^{11} \mathrm{Bi}$ - and multiphoton absorption offers the advantage of spatially resolved irradiation and higher 50 selectivity than mono-photonic excitation, especially when femtosecond pulses are used. ${ }^{11}$ However, the light intensities required for the simultaneous absorption of two or several photons are very hard to achieve when treating tumours within the human/mammalian body, because the two- and multi-photon 55 absorption cross-sections are generally low. ${ }^{11}$

Early detection of tumours and especially their metastases is crucial for cancer treatment. Traditionally, tumour detection is achieved by various methods, including magnetic resonance imaging and computerized tomography. The recent advances in 60 life science and bioengineering permit the transfection, cellular expression, and real-time imaging of light-emitting proteins, such as Renilla luciferase (Ruc), bacterial luciferase (Lux), or fluorescent proteins, such as firefly luciferase (Luc), green fluorescent protein (GFP), or Ruc-GFP fusion protein. ${ }^{12}$ All of ${ }_{65}$ these marker proteins, which generate bioluminescence by chemical processes ${ }^{12}$, have been successfully employed for tumour detection. Since no excitation light is required, there is no background fluorescence and, consequently, a much improved signal to noise ratio. It has also been demonstrated that certain 70 bacteria (e.g. Clostridium and Bifidobacterium ${ }^{13}$ ), viruses ${ }^{14}$, and neural stem cells ${ }^{15}$, when administered systemically, are able to gain entry to and replicate selectively in tumours. In addition many tissue/tumour specific promoters have been cloned, allowing transgene expression specifically in tumour tissues. ${ }^{16}$

75 Here we describe the transfection of murine neural stem cells with Gaussia luciferase. Gaussia, a calanoid copepod, about $6 \mathrm{~mm}$ in size, is a member of the planktonic community. Gaussia luciferase has a molecular weight of only $19.9 \mathrm{kDA}$, which makes it the smallest luciferase using coelenterazine as substrate. ${ }^{17-19} \mathrm{It}$ 80 is noteworthy that Gaussia luciferase is approx. 750-fold brighter than native Renilla luciferase (when consuming the same amount of substrate). ${ }^{20}$ In the work reported here, neural stem cells secreting Gaussia luciferase were cultured. Murine B16F10 
melanoma cells were then treated with the resulting culture medium containing Gaussia luciferase and its substrate coelenterazine (COEL). ${ }^{16-19}$ ALA (5-aminolevulinic acid) was given to the B16F10 cells prior to PDT. ALA is the prodrug for 5 the biosynthesis of the photosensitizer protoporphyrin IX (PpIX) in the cancer cells' mitochondria. ${ }^{21,22}$ The effects all three components (ALA, COEL, and bioluminescence alone) on the cancer cells as a function of time is discussed in this report. The structures of ALA, protoporphyrin IX, and coelenterazine are 10 shown in Scheme 1.

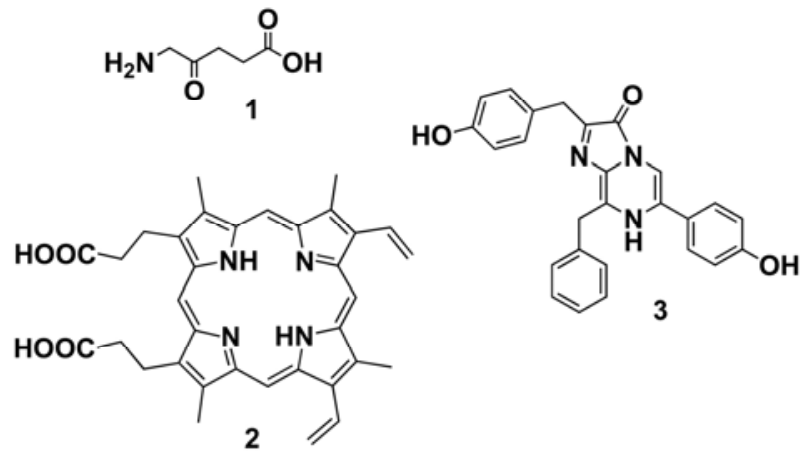

Scheme 1: Structures of aminolevulinic acid (1), protoporphyrin IX (2) and coelenterazine (3).

\section{Results and Discussion}

${ }_{15}$ The first attempt to use bioluminescence from NIH $3 \mathrm{~T} 3$ murine fibroblasts, which were transfected with firefly luciferase, was reported in 2003 by A. J. MacRobert and coworkers. ${ }^{23}$ The cells were loaded with D-luciferin and the photosensitizer rose bengal featuring a quantum yield of singlet-oxygen sensitization of ${ }_{20} \Phi_{\Delta}=0.75 \pm 0.05$ in aqueous media. ${ }^{23}$ The emission spectrum of luciferase/ATP oxyluciferin and the absorption spectrum of rose bengal match very nicely. In such a case, the excitation of rose bengal can be achieved by either reabsorption of the bioluminescence or through Förster energy transfer. ${ }^{24}$

${ }_{25}$ The bioluminescence from firefly luciferase requires D-luciferin and ATP. In the presence of luciferase, D-luciferin and rose bengal, the cell survival rate dropped from $100 \%$ to $11 \%$ after $24 \mathrm{~h} .^{23}$ Although this initial study demonstrated the potential of in situ PDT, it had the following drawbacks with respect to possible 30 in vivo applications: 1) the cell that is to be treated has to be transfected with the gene of a bioluminescent enzyme first; and 2) rose bengal is a very good sensitizer for technical applications, such as vitamin D synthesis ${ }^{25}$, however, it is toxic to cells. ${ }^{26} \mathrm{~A}$ suitable therapeutic system should comprise a non-toxic 35 sensitizer and cells that are able to migrate to solid tumours and secrete the bioluminescent enzyme. The singlet oxygen sensitization by the sensitizer should be sufficient to permit the efficient generation of singlet oxygen, even in the usually hypoxic tumour environment.

A Neural Stem Cell-Based in Vitro System for Photodynamic Therapy of Melanoma

Mouse neural stem cells (C17.2 immortalized cells) were transfected with a plasmid containing the gene for Gaussia
${ }_{45}$ luciferase (Nanolight). ${ }^{27}$ Mouse neural stem cells (NSC) were used because they are known to "home" to numerous solid tumours. ${ }^{15}$ The pGLuc-basic-1 vector contains the "humanized" coding sequence for secreted Gaussia luciferase (gLuc), for use in mammalian cells. The medium containing gLuc secreted from ${ }_{50}$ the C17.2 cells was harvested at 24 hours and used to treat B16F10 mouse melanoma cells that had been independently cultured and treated with the supernatant from the mouse neural stem cells. Figure 1 shows the cell cultures of the mouse neural stem cells (A) and B16F10 mouse melanoma cells (B).

55

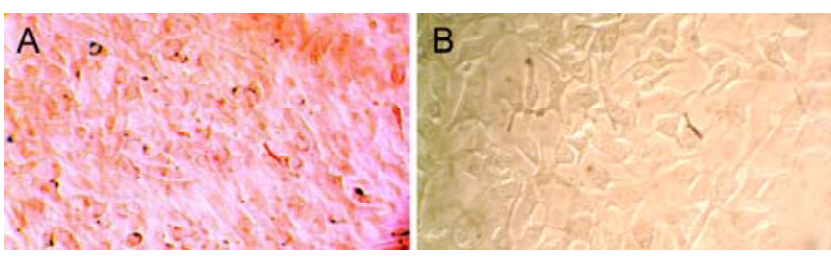

Figure 1: A: C17.2 neural stem cells (mouse NSC)), 20x magnification; B: B16F10 melanoma cells, 20x magnification.

The emission spectrum of the bioluminescence emitted from the supernatant in the presence of coelenterazine is shown in Figure ${ }_{60} 2$. The bioluminescence occurs during the oxidation of coelenterazine to coelenteramide by gLuc, as shown in Scheme 2.

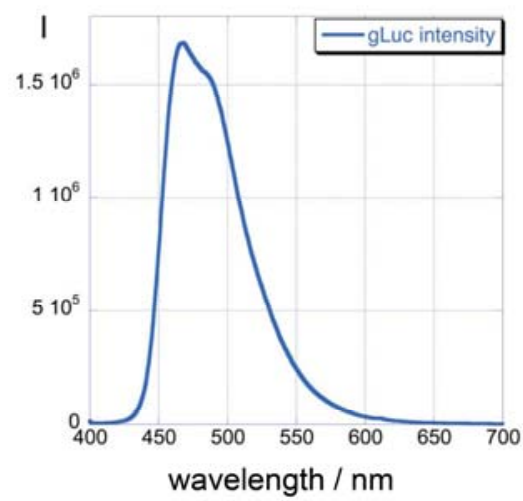

Figure 2: Emission from gLuc: $2 \mathrm{~mL}$ of supernatant from the medium in which gLuc transfected neural stem cells (NSC) have been grown for $24 \mathrm{~h}$, 65 to which was added $8 \mu \mathrm{l}$ of coelenterazine $(1 \mathrm{mg} / \mathrm{mL})$ in $\beta$-cyclodextrin, ratio coelenterazine:cyclodextrin $=1: 50)$.

Figure 3 shows the kinetics of light emission from the supernatant of the $\mathrm{C} 17.2$ cells in the presence of coelenterazine.
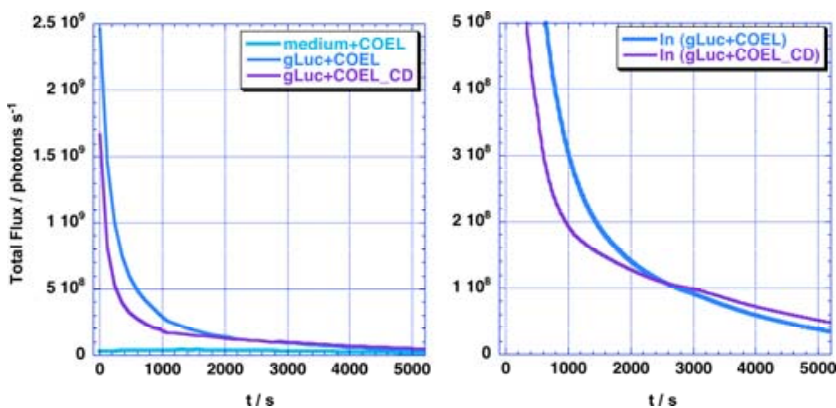

70 Figure 3: Time-profile of the bioluminescence occurring from gLuc: 100 $\mu \mathrm{L}$ of supernatant from the medium, in which gLuc transfected neural stem cells (NSC) have been grown for $24 \mathrm{~h}, 8 \mu \mathrm{l}$ of coelenterazine $(1 \mathrm{mg} / \mathrm{mL})$ or $8 \mu \mathrm{l}$ of coelenterazine in $\beta$-cyclodextrin, ratio coelenterazine:cyclodextrin $=1: 50)$. 
Secreted gLuc is very stable under the conditions reported here, as indicated by first-order kinetics after the addition of coelenterazine. It is noteworthy that secreted gLuc retained its catalytic activity for up to 1 year at $195 \mathrm{~K}$ and for up to one month 5 at $277 \mathrm{~K}$. The observed bisexponential first order kinetics can be explained by the heterogeneity of the supernatant from culturing gLuc secreting NCS's. Although coelenterazine (COEL) is more hydrophobic $\left(\log \mathrm{P}=3.406^{28}\right)$ than its' $\beta$-cyclodextrin (COEL_CD) adduct $\left(\log \mathrm{P}=-1.2^{28}\right)$, the addition of free COEL 10 resulted in a higher photon flux within $90 \mathrm{~min}$. after mixing (total measured photon flux: $1.37 \pm 0.05 \times 10^{12}$ photons (COEL) vs. $9.90 \pm 0.05 \times 10^{11}$ photons (COEL_CD). The crossover between the bioluminescence decay of COEL and the COEL-CD was observed after $2535 \mathrm{~s}$ at low photon flux $\left(1.083 \times 10^{8}\right.$ photons s$\left.{ }^{-1}\right)$.

15 In spite of its higher hydrophobicity, free COEL is soluble in our culture medium at a concentration of $1.75 \times 10^{-8} \mathrm{~mol}$. We attribute its higher efficiency of bioluminescence to the fact that only free COEL reacts with gLuc. Therefore, the catalytic activity of gLuc depends on the dissociation of the supramolecular ${ }_{20}$ COEL-CD complex. The half-lives of the gLuc catalyzed bioluminescence of COEL were determined to be $263 \mathrm{~s} \pm 10 \mathrm{~s}\left(\mathrm{k}_{1}=\right.$

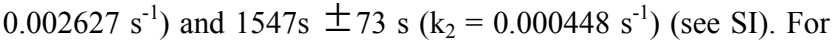
the COEL-CD complex, we have obtained $175 \mathrm{~s} \pm 8 \mathrm{~s}\left(\mathrm{k}_{1}=\right.$ $\left.0.003961 \mathrm{~s}^{-1}\right)$ and $2278 \mathrm{~s} \pm 88 \mathrm{~s}\left(\mathrm{k}_{2}=0.000304 \mathrm{~s}^{-1}\right)$ under 25 identical conditions.

The maximal photon total flux, as measured by an $\operatorname{IVIS}^{\circledR}$ Lumina Live Imaging device (Caliper Life Sciences) and calculated by integrating Figure 3 was $1.368 \pm 0.005 \times 10^{12}$ photons. However,

30 the detection geometry of the IVIS system does not permit the straightforward calculation of bioluminescence conversion efficiencies. $1.05 \times 10^{16}$ molecules of coelenterazine were added to the well. Only $0.026 \%$ of coelenterazine molecules emitted photons that reached the IVIS detection system. Considering the 35 IVIS geometry and depending on assumptions for scattering and self-absorption, the coelenterazine to bioluminescence conversion efficiency within $90 \mathrm{~min}$. is approximately 10-50 times higher.

\section{Gaussia-Luciferase Based Photodynamic Therapy of Mouse Melanoma Cells}

${ }_{40} \mathrm{We}$ have used the supernatant from gLuc-expressing neural stem cells (NSCs) to study the photodynamic effect of protoporphyrin IX on B16F10 (mouse melanoma) cells. gLuc expressing NSCs $\left(5 \times 10^{4}\right.$ cells) were suspended in $1.0 \mathrm{ml}$ of their growth medium. The B16F10 cells were incubated at $310 \mathrm{~K}$ with $5 \% \mathrm{CO}_{2}$ for 24 45 hours, after which ALA $(2 \mathrm{mMol})$ was added. ALA is the substrate for the biosynthesis of protoporphyrin IX (PpIX) in the mitochondria of the cancer cells. Twenty four hours after changing the aqueous buffer to the supernatant from culturing the gLuc transfected NSCs, coelenterazine $(8 \mu \mathrm{g} / \mu \mathrm{l})$ was added as 50 water-soluble $\beta$-cyclodextrin-complex. After addition of coelenterazine, viable cancer cell numbers were analyzed over a 36 hours period using an MTT assay. ${ }^{29}$ All experiments were done in triplicate and repeated at least three times. The results are shown in Figure 4 (12h after treatment), Figure 5 (24h after 55 treatment) and Figure 6 ( $36 \mathrm{~h}$ after treatment). To distinguish the effect of this photodynamic therapy system on B16F10 cell viability and cytotoxic/growth augmenting effects that occur in the dark, the following control groups were used: 1) B16F10 cells (no treatment); 2) B16F10 cells in the presence of ALA 60 (aminolevulinic acid); 3) B16F10 cells in the presence of coelenterazine; 4) B16F10 cells in the presence of coelenterazine

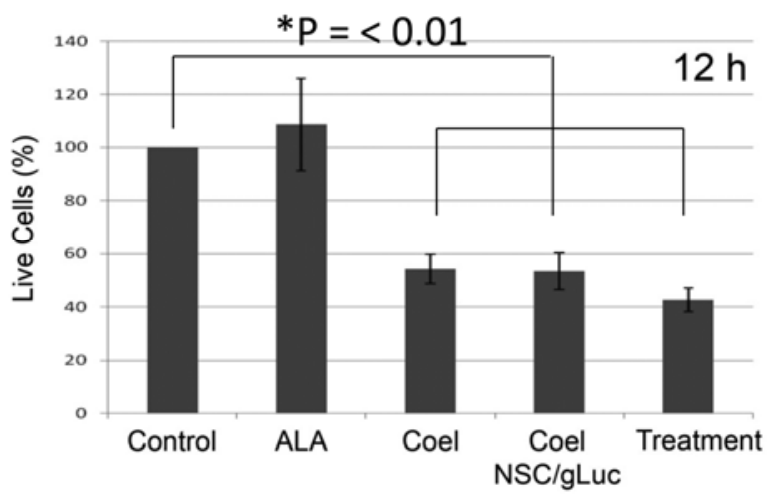

and gLuc (=bioluminescence). The treatment group consisted of B16F10 cells that were cultured in the presence of gLuc, ALA $\left(2 \mathrm{mmol} \mathrm{L}^{-1}\right)$ and coelenterazine $\left(8 \mu \mathrm{g} / 100 \mu \mathrm{L}^{-1}\right)$.

65 Figure 4: Effect on B16F10 melanoma cell viability of control cells (no treatment), ALA (aminolevulinic acid) alone, coelenterazine alone, coelenterazine and $\mathrm{NSC} / \mathrm{gLuc}$ (=bioluminescence), or full treatment (NSC/gLuc, ALA $\left(2 \mathrm{mmol} \mathrm{L}^{-1}\right)$, coelenterazine $(8 \mu \mathrm{g} / 100 \mu \mathrm{L}$ medium $)$, $12 \mathrm{~h}$ after treatment.

70

Figure 4 indicates that ALA may be able to boost the cancer growth, when given alone. ALA is a precursor of porphyrin, heme, and bile pigments, and it is metabolized into protoporphyrin IX (PpIX) in the course of heme synthesis. ${ }^{30}$ The 75 autofluorescence of PpIX and heme is known to be a predictor of cancer development, because the biosynthesis of porphyrins is upregulated in many cancers. ${ }^{31-33}$ It is apparent that enhanced biosynthesis of porphyrins in B16F10 melanoma cells due to the presence of the precursor ALA increases the melanoma cell 80 growth. Porphyrins are essential molecules within cells and have multiple roles in essential cellular processes such as the mitochondrial electron transport chain, free-radical detoxification, and metabolic activity. Therefore, upregulating porphyrin biosynthesis is beneficial for the cancer cell. ${ }^{34}$

${ }_{85}$ Coelenteramide, which is formed from coelenterazine through enzymatic and non-enzymatic oxidation ${ }^{17-19}$ (see Scheme 2), shows discernible cell toxicity. The addition of gLuc apparently does not significantly increase this toxicity. This finding clearly demonstrated that the blue light emitted by the COEL/gLuc 90 system does not harm the B16F10 cells, although the black melanomas are able to absorb the light. Apparently, the photon flux of the bioluminescence is not high enough to cause detectable harm. A detailed ANOVA analysis of these data, which is provided in the SI section, clearly indicates that the ${ }_{95} \mathrm{COEL}$ and $\mathrm{COEL} / \mathrm{gLuc}$ groups cannot be distinguished from the treatment group $12 \mathrm{~h}$ after PDT. 


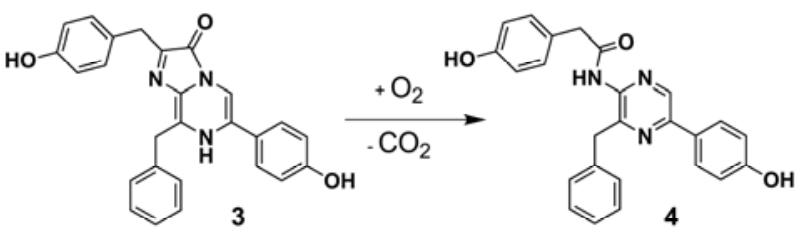

Scheme 2: The oxidation of coelenterazine (3) to coelenteramide (4) is catalyzed by gLuc. In the absence of gLuc, coelenterazine is slowly decomposed (within $48 \mathrm{~h}$ ) in aerated aqueous buffer in the presence of three $\mathrm{Ca}^{2+}$ ions. ${ }^{17-19}$

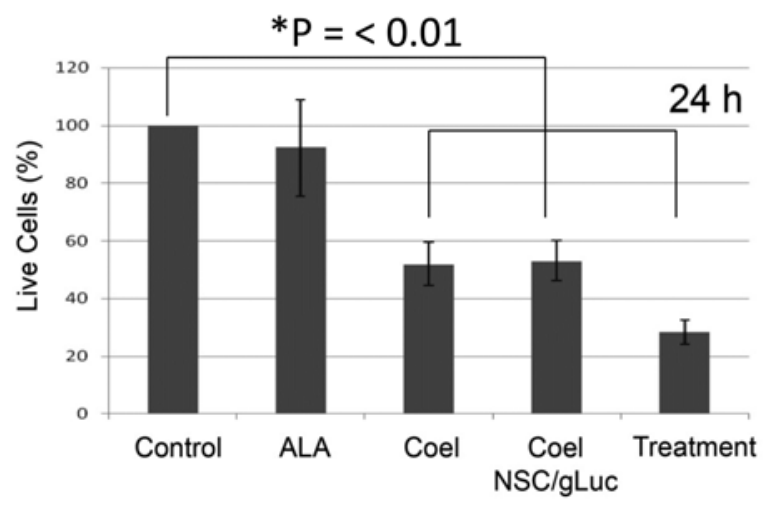

5 Figure 5: Effect on B16F10 melanoma cell viability of control cells (no treatment), ALA (aminolevulinic acid) alone, coelenterazine alone, coelenterazine and NSC/gLuc (=bioluminescence), or full treatment (NSC/gLuc, ALA ( $\left.2 \mathrm{mmol} \mathrm{L}^{-1}\right)$, coelenterazine $(8 \mu \mathrm{g} / 100 \mu \mathrm{Lmedium})$ ), $24 \mathrm{~h}$ after treatment.

10 Figure 5 shows that $24 \mathrm{~h}$ after treatment, all groups remain essentially unchanged, except the treatment group, which is at that time statistically significantly reduced. This finding can be regarded as proof that stem cell based photodynamic therapy is really working in vitro. The delayed response of B16F10 15 melanoma cells to PDT is an indication of apoptosis as the mode of cell death. ${ }^{35}$ It must be noted that an ANOVA analysis of the data summarized in Figure 5 indicates that the COEL and COEL/gLuc control groups cannot be distinguished from the treatment group $24 \mathrm{~h}$ after PDT.

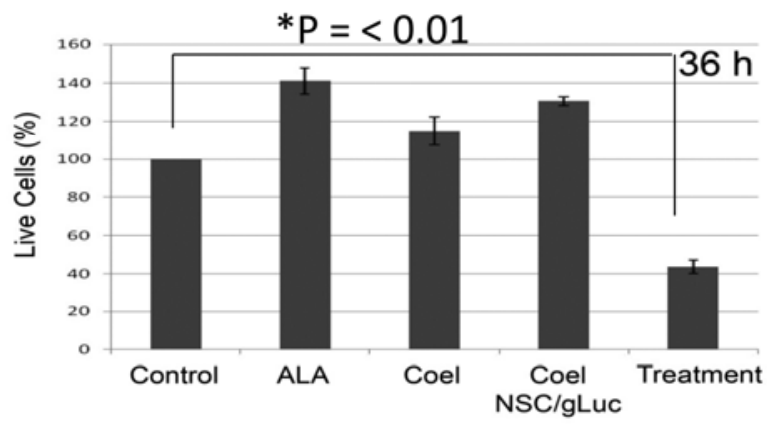

Figure 6: Effect on B16F10 melanoma cell viability of control cells (no treatment), ALA (aminolevulinic acid) alone, coelenterazine alone, coelenterazine and NSC/gLuc (=bioluminescence), or full treatment (NSC/gLuc, ALA $\quad\left(2 \mathrm{mmol} \mathrm{L}^{-1}\right)$, coelenterazine $(8 \mu \mathrm{g} / 100 \mu$ Lmedium)), 25 $36 \mathrm{~h}$ after treatment.
Figure 6 shows that the irradiated and non-irradiated mouse melanoma cells have recovered from the coelenteramide toxicity after $36 \mathrm{~h}$. ALA is still beneficial to melanoma growth in vitro.

${ }_{30}$ However, there is virtually no recovery of the treated group of cells. This finding is again in agreement with the hypothesis of apoptosis as the mode of cell death. It also shows that all components of the treatment (ALA, COEL and gLuc) are required to result in a lasting treatment effect! As ANOVA 35 indicates, 36h after PDT, the treatment group is significantly different from all other groups $(\mathrm{p}<0.001)$.

\section{Experimental}

The synthesis of aminolevulinic acid (ALA) has been performed 40 according to a published procedure. ${ }^{36}$ This team has developed a novel synthesis for coelenterazine (COEL) ${ }^{37}$ Coelenterazine (1 $\mathrm{g} / \mathrm{mL})$ was dissolved in acidified $\mathrm{MeOH}(5 \mathrm{mmol} \mathrm{HCl})$ under Ar and $\beta$-cyclodextrin (molar ratio 50:1) was added. After the mixture had completely dissolved, the solvent was removed in

${ }_{45}$ high vacuum. The white solid was then dissolved in PBS buffer, resulting in a coelenterazine concentration of $1 \mathrm{~g} / \mathrm{mL}$.

gLuc transfection of C17.2 mouse neural stem cells

The immortalized C17.2 mouse neural stem cells (NSC) have 50 been transfected using the pCMV-Gluc-1 plasmid (Cat\#202, humanized Gaussia luciferase with secretory signal) from NanoLight Technology, Pinetop, AZ 85935. Due to the secretory signal, GLuc is secreted into the cell medium of cultured mammalian cells upon expression. NSCs were plated in 24 well 55 plates in phenol red free NSC medium (Dulbecco's modified Eagle medium (DMEM; Invitrogen, Carlsbad, CA) supplemented with $10 \%$ fetal bovine serum (FBS; Sigma-Aldrich St. Louis, $\mathrm{MO}$ ), 5\% horse serum (Invitrogen), 1\% glutamax (Invitrogen), and $1 \%$ penicillin/streptomycin(Invitrogen)) at 40,000 cells per 60 well and incubated at $37{ }^{\circ} \mathrm{C}$ for 24 hours. After 24 hours, cells were at $70-80 \%$ confluence. Medium was replaced with fresh NSC medium without phenol red. For each well of 24 well plate, $1 \mu \mathrm{g}$ of pCMV-Gluc-1 plasmid was diluted in $49 \mu \mathrm{L}$ serum free medium and $2 \mu \mathrm{L}$ of TurboFect ${ }^{\mathrm{TM}}$ in vitro transfection reagent ${ }_{65}$ (Fermentas, Life Science) was added to the medium and mixed well by vortexing. After incubation of the plasmid mixture at 25 ${ }^{\circ} \mathrm{C}$ for 20 minutes, $52 \mu \mathrm{L}$ of the mixture was added to each well and gently mixed by rocking the plate. Then, cells were further incubated for 24 hour to allow secretion of gLuc.

70

Bioluminescence from gLuc

$100 \mu \mathrm{L}$ of supernatant from the medium in which gLuc transfected neural stem cells (NSC) had been grown for $24 \mathrm{~h}$ at $310 \mathrm{~K}$, was added to $8 \mu \mathrm{l}$ of coelenterazine $(1 \mathrm{~g} / \mathrm{mL})$ in $\beta$ 75 cyclodextrin, ratio coelenterazine:cyclodextrin $=1: 50)$. The resulting mixture was then imaged using an IVIS Lumina II system at $300 \mathrm{~K}$. The bioluminescence spectrum has been recorded using an ISA SPEX Fluoromax-2.

${ }_{80}$ Cultures of C17.2 and B16F10 cells (ATCC (Manassas,VA)) C17.2 cells were cultured in Dulbecco's modified Eagle medium (DMEM; Invitrogen, Carlsbad, CA) with 10\% fetal bovine serum (FBS Sigma-Aldrich), 5\% horse serum (Invitrogen), 1\% glutamax (Invitrogen), and $1 \%$ penicillin/streptomycin 
(Invitrogen). B16F10 cells were cultered in DMEM( Invitrogen, Carlsbad, CA) with 10\% FBS (Sigma-Aldrich, St. Louis, MO) and $1 \%$ penicillin/streptomycin (Invitrogen)with 10\% FBS (Fetal Bovine Serum), 5\% Horse serum, 1\% Glutamax, 1\% Penstrap. ${ }_{5}$ Cells were grown overnight as monolayers at a concentration of 20,000 cells $/ \mathrm{cm} 2$ in $25-\mathrm{cm} 2$ flasks in $5-\mathrm{mL}$ medium at $310 \mathrm{~K}$ and $5 \% \mathrm{CO} 2$. After attaining 70\% confluence (after $24 \mathrm{~h}$ ) the growth medium was removed. Trypsin EDTA $(1 \mathrm{~mL})$ was added to facilitate the detachment of the cells. After $1 \mathrm{~min} ., 3 \mathrm{~mL}$ medium 10 was added to stop the Trypsin EDTA reaction. The cells were then replated (at a 1:2 dilution). The conditioned medium (1:5, medium from culturing gLuc C17.2 cells:fresh medium of B16F10 without phenol red) was used for replacing medium of the B16F10 cells. This system was then used for the in-vitro PDT 15 experiments.

\section{MTT Assay}

3-(4,5-Dimethylthiazol-2-yl)-2,5-diphenyltetrazolium bromide (MTT) was dissolved in PBS at $5.0 \mathrm{mg} / \mathrm{mL}$ (MTT reagent). MTT 20 solubilization buffer was prepared by dissolving $10 \%(\mathrm{w} / \mathrm{v})$ sodium dodecylsulfate and $0.1 \mathrm{M} \mathrm{HCl}$ in bidest. water. To assay cell viability, MTT reagent solution $1: 10 \quad(\mathrm{v} / \mathrm{v}$, reagent solution/cell medium) was added to the cells and incubated at $310 \mathrm{~K}$ for $4 \mathrm{~h}$. Then, MTT solubilization buffer $25($ medium/buffer=1:1) was added, followed by overnight incubation at $310 \mathrm{~K}$. The absorbance at $550 \mathrm{~nm}$ and $690 \mathrm{~nm}$ (as background) were measured using a plate reader (Spectra MAX190, Molecular Devices). The difference in absorbance between the two wavelengths is indicative of the number of live 30 cells.

\section{Experimental Design}

Statistical analyses of the measured cell viabilities have been performed using the program WinSTAT (A-Prompt Corporation, ${ }_{35}$ Lehigh Valley, PA). ${ }^{38}$ The means of the experimental groups have been evaluated to confirm that they meet the normality assumption. To evaluate the significance of overall differences in cell viability between all in vitro groups, statistical analysis has been performed by analysis of variance (ANOVA). A p-value less 40 than 0.01 has been considered as significant.

\section{Conclusions}

Addition of media conditioned by Gaussia luciferase- secreting neural stem cells generates blue light after the addition of 45 coelenterazine that can significantly attenuate B16 melanoma cells pre-exposed to 5-aminolevulinic acid. The attenuation effect was observed at 24 hours after treatment and was most significant relative to controls at 36 hours after PDT.

\section{${ }_{50}$ Acknowledgements}

DT thanks Dr. V. Ourednik (Iowa State University) for the precious gift of mouse neural stem cells (C17.2 immortalized cells, originally developed by Dr. Evan Snyder). This research is based upon work supported by the National Science Foundation 55 under Award No. CBET 933701.

\section{Notes and references}

${ }^{a}$ Kansas State University, Anatomy \& Physiology, Manhattan, KS 66506, USA. Fax: 001785532 4557; Tel: 001785532 4509; E-mail: tbs3@

60 vet.k-state.edu; troyer@vet.k-state.edu

${ }^{b}$ Kansas State University, Chemistry, Manhattan, KS 66506, USA. Fax: 001785532 6817; Tel: 001785532 6666; E-mail: sbossman@kstate.edu

$\dagger$ Electronic Supplementary Information (ESI) available: $\left[{ }^{1} \mathrm{H}-\mathrm{NMR}\right.$ of 65 aminolevulinic acid, ANOVA analysis of the in-vitro PDT experiment and analysis of bioluminescence kinetics]. See DOI: 10.1039/b000000x/

\section{References}

1 S. Marchini, M. D'Incalci and M. Broggini, Curr Med Chem Anticancer Agents, 2004, 4, 247-262.

$2 \mathrm{http} / /$ www.cancer.gov/cancertopics/pdq/prevention/skin/

3 D. E. Dolmans, D. Fukumura and R. K. Jain, Nat Rev Cancer, 2003, 3, 380-387.

4 U.S. Food and Drug Administration (December 2003). Approved claims for palliative line therapy. Retrieved December 29, 2003, from: http://www.accessdata.fda.gov

5 B. C. Wilson and S. L. Jacques, Ieee J Quantum Elect, 1990, 26, 21862199.

6 P. Taroni, A. Pifferi, A. Torricelli, D. Comelli and R. Cubeddu, Photoch Photobio Sci, 2003, 2, 124-129.

7 Haedersdal, M.; Togsverd-Bo, K.; Wulf, H. C. Evidence-based review of lasers, light sources and photodynamic therapy in the treatment of acne vulgaris., JEADV 2008, 22, 267-78.

8 M. H. Schmidt, D. M. Bajic, K. W. Reichert, T. S. Martin, G. A. Meyer and H. T. Whelan, Neurosurgery, 1996, 38, 552-556.

9 H. van den Bergh, J. Mizeret, J.-F. Theumann, A. Woodtli, R. Bays, D. Robert, P. Thielen, J.-M. Philippoz and D. Braichotte, Proceedings of SPIE-The International Society for Optical Engineering, 1995, 2631, 173-198.

10 M. P. Melancon, W. Lu, Z. Yang, R. Zhang, Z. Cheng, A. M. Elliot, J. Stafford, T. Olson, J. Z. Zhang and C. Li, Mol Cancer Ther, 2008, 7, 1730-1739.

11 K. Ogawa and Y. Kobuke, Anti-Cancer Agent Me, 2008, 8, 269-279.

12 Y. A. Yu, T. Timiryasova, Q. Zhang, R. Beltz and A. A. Szalay, Anal Bioanal Chem, 2003, 377, 964-972.

13 M. Babincova, P. Sourivong and P. Babinec, Med Hypotheses, 2000, 54, 180-181.

14 B. Denes, N. Fodor, A. Obenaus and I. Fodor, Open Biotechnology Journal 2008, 2, 252-261.

15 R. S. Rachakatla, S. Balivada, G. M. Seo, C. B. Myers, H. W. Wang, T. N. Samarakoon, R. Dani, M. Pyle, F. O. Kroh, B. Walker, X. X. Leaym, O. B. Koper, V. Chikan, S. H. Bossmann, M. Tamura and D. L. Troyer, Acs Nano, 2010, 4, 7093-7104.

16 C. Moonen, In Vivo MR Techniques in Drug Discovery and Development, 2006, 301-311.

17. B. A. Tannous, D. E. Kim, J. L. Fernandez, R. Weissleder and X. O. Breakefield, Mol Ther, 2005, 11, 435-443.

18 U. Griesenbach, C. C. Vicente, M. J. Roberts, C. X. Meng, S. Soussi, S. Xenariou, P. Tennant, A. Baker, E. Baker, C. Gordon, C. Vrettou, D. McCormick, R. Coles, A. M. Green, A. E. Lawton, S. G. SumnerJones, S. H. Cheng, R. K. Scheule, S. C. Hyde, D. R. Gill, D. D. Collie, G. McLachlan and E. W. F. W. Alton, Biomaterials, 2011, 32, 2614-2624.

19 Y. Inoue, F. Sheng, S. Kiryu, M. Watanabe, H. Ratanakanit, K. Izawa, A. Tojo and K. Ohtomo, Mol Imaging, 2011, 10, 377-385.

20 B. Ballou, C. Szent-Gyorgi and G. Finley, in 11th international symposium on bioluminescence and chemiluminescence., Asilomar, CA, 2000.

21 J. Regula, A. J. Macrobert, A. Gorchein, G. A. Buonaccorsi, S. M. Thorpe, G. M. Spencer, A. R. W. Hatfield and S. G. Bown, Gut, 1995, 36, 67-75. 
22 T. J. Beck, F. W. Kreth, W. Beyer, J. H. Mehrkens, A. Obermeier, H. Stepp, W. Stummer and R. Baumgartner, Laser Surg Med, 2007, 39, 386-393.

23 T. Theodossiou, J. S. Hothersall, E. A. Woods, K. Okkenhaug, J. Jacobson and A. J. MacRobert, Cancer Res, 2003, 63, 1818-1821.

24 A. Roda, M. Guardigli, E. Michelini and M. Mirasoli, Anal Bioanal Chem, 2009, 393, 109-123.

25 M. Morisaki, J. Rubio-Lightbourn and N. Ikekawa, Chemical \& Pharmaceutical Bulletin, 1973, 21, 457-458.

26 S. H. Mousavi, J. Tavakkol-Afshari, A. Brook and I. Jafari-Anarkooli, Food Chem Toxicol, 2009, 47, 855-859.

$27 \mathrm{http}: / /$ www.nanolight.com/nanoligh.htm

28 A. Petrauskas, E. A. Kolovanov, Perspectives in Drug Discovery and Design, 2000, 19, 99-116.

29 A. H. Cory, T. C. Owen, J. A. Barltrop and J. G. Cory, Cancer Commun, 1991, 3, 207-212.

30 M. Ishizuka, F. Abe, Y. Sano, K. Takahashi, K. Inoue, M. Nakajima, T. Kohda, N. Komatsu, S. Ogura and T. Tanaka, Int Immunopharmacol, 2011, 11, 358-365.

31 M. H. Bellini, E. L. Coutinho, L. C. Courrol, F. R. D. Silva, N. D. Vieira and N. Schor, J Fluoresc, 2008, 18, 1163-1168.

32 L. C. Courrol, F. R. D. Silva, E. L. Coutinho, M. F. Piccoli, R. D. Mansano, N. D. Vieira, N. Schor and M. H. Bellini, J Fluoresc, 2007, 17, 289-292.

33 K. Onizawa, N. Okamura, H. Saginoya and H. Yoshida, Oral Oncol, 2003, 39, 150-156.

34 P. Krishnamurthy and J. D. Schuetz, Curr Pharm Biotechno, 2011, 12, 647-655.

35 J. Saczko, J. Kulbacka, A. Chwilkowska, M. Drag-Zalesinska, T. Wysocka, M. Lugowski and T. Banas, Folia Histochem Cyto, 2005, 43, 129-132.

36 M. S. Kang, D. M. Kim, J. S. Kim and J. H. Jeong, Arch Pharm Res, 2005, 28, 1111-1113.

37 T. B. Shrestha, D. L. Troyer, S. H. Bossmann, J Org Chem, submitted.

38 A. Riva, A. S. Carpentier, B. Torresani and A. Henaut, Comput Biol Chem, 2005, 29, 319-336. 